\title{
High-pressure water-jet-assisted machining of Ti555-3 titanium alloy: investigation of tool wear mechanisms
}

\author{
Y. Ayed $^{1} \cdot$ G. Germain ${ }^{1}$
}

\begin{abstract}
The main objective of this study is to investigate uncoated tungsten carbide tool wear mechanisms for high-pressure waterjet machining of the Ti555-3 titanium alloy. A comparative study has been undertaken (i.e. conventional versus assisted machining) based on numerous experimental tests. These tests have been accompanied by the measurement of the cutting forces and flank wear. It is concluded that the high-pressure water-jet assistance can greatly increase tool life compared to conventional machining, for all cutting conditions. The gain in tool life depends on the severity of the cutting condition. The analyses performed for each test (i.e. SEM, EDS and 3D profilometer) made it possible to monitor the tool wear and to investigate the main wear mechanisms. Based on these analyses, adhesion wear appears to be the most influential mechanism and it is accelerated by an increase in water-jet pressure. Monitoring of the wear profile made it possible to study the evolution of crater wear and material chipping during machining.
\end{abstract}

Keywords Tool wear $\cdot$ High pressure $\cdot$ Cutting forces $\cdot$ Titanium alloy $\cdot$ Machining

\section{Introduction}

The machining of titanium alloys is often challenging due to their excellent mechanical properties and their high chemical reactivity with most cutting tool materials [1]. The past decades have seen the development of new nearbeta alloys that have better mechanical properties, improved fracture toughness and good hardenability [2, 3]. However, these alloys such as Ti-10V-2Fe-3Al and Ti-5Al-5V-5Mo$3 \mathrm{Cr}$ raise significant machinability problems [4], leading to severely reduced cutting conditions. This in turn leads to lower productivity [5].

The machinabilty of these alloys has already been the subject of some research. A comparative study concerning the machining of Ti555-3 (near beta) and Ti-6Al-4V $(\alpha+\beta)$ titanium alloys has been carried out by Arrazola et al. [6]. This study showed that the machinability of the Ti555-3 alloy is reduced by about $44 \%$ compared to the Ti-6Al$4 \mathrm{~V}$ (the reference material). Moreover, the specific feed

Y. Ayed

yessine.ayed@ensam.eu

1 Arts et Métiers ParisTech, LAMPA, 2 bd du Ronceray, 49035 Angers Cedex, France force and the specific cutting force are 35 and $20 \%$ higher, respectively. Also, for a wear criterion of $V B=0.3 \mathrm{~mm}$, with a cutting speed ranging from 40 to $90 \mathrm{~m} / \mathrm{min}$ and a machining time of $15 \mathrm{~min}$, the optimum cutting speed was determined to be $45 \mathrm{~m} / \mathrm{min}$ for the Ti555-3 alloy and $80 \mathrm{~m} / \mathrm{min}$ for the Ti-6Al-4V alloy. A similar study has been conducted by Nouari et al. [7] based on orthogonal cutting tests. This research showed that Ti-6Al-4V alloy is more sensitive to thermal softening; however, Ti555-3 alloy is more sensitive to strain rate hardening. The authors demonstrated that the main tool wear modes are adhesion and diffusion. Moreover, the cutting forces are 20 to $40 \%$ higher for the Ti555-3 (depending on the tool rake angle). According to Bai et al. [5], adhesion, diffusion and abrasion are the main tool wear mechanisms when machining the Ti$10 \mathrm{~V}-2 \mathrm{Fe}-3 \mathrm{Al}$ titanium alloy. This lower machinablility has been explained by [8] as the result of higher mechanical properties, cutting temperatures, adhesion tendency and chip segmentation frequency.

In order to meet this challenge, various solutions have been proposed. Among them is the development of new tool coatings and more efficient lubricants. Good performance has been obtained using self-lubricating $\mathrm{Ti} \mathrm{B}_{2}$ PVD coatings [9]. This improves tool life by approximately $60 \%$ compared to uncoated and $70 \%$ compared to $\mathrm{Ti} A l N$ 
coated tools. This is mainly due to the formation of a $\mathrm{B}_{2} \mathrm{O}_{3}$ phase that acts as a lubricant. The impact of the lubricant type on tool wear when machining the Ti-6Al-4V alloy has been studied by Moura et al. [10]. This study demonstrated that the use of a solid lubricant, notably $\mathrm{MoS}_{2}$, results in an increase in tool life, reduces cutting forces and minimizes frictional effects. This is due to the ability of the solid lubricant to penetrate the cutting zone. However, in order to achieve better results, other strategies must be employed. At present, the most interesting and promising approach consists of adding assistance to machining such as cryogenic assistance, laser assistance and high-pressure water-jet assistance.

Laser-assisted machining has been employed to enhance the machinablity of titanium alloys such as Ti-10V-2Fe$3 \mathrm{Al}$, Ti-6Cr-5Mo-5V-4Al and Ti-6Al-4V [11-13]. This technique has been shown to reduce cutting forces up to $60 \%$. However, the influence of the assistance on tool wear remains debatable. As opposed to this technique, cryogenicassisted machining consists of cooling the tool/chip interface with a liquefied gas such as liquid nitrogen and $\mathrm{CO}_{2}$. The use of this technique has been effective in limiting adhesive wear, improving surface roughness and increasing tool life [14-16]. Recent studies [17, 18] showed a great improvement in surface integrity when machining Ti-6Al$4 \mathrm{~V}$ titanium alloy.

Under certain cutting conditions, the best results in terms of tool life and productivity have been obtained using high-pressure water-jet assistance (HPWJA). This technique consists of spraying a high-pressure water jet between the tool rake face and the chip. On the one hand, the mechanical action of the jet breaks the chips and on the other hand it cools the tool and the workpiece.

In this context, several studies have been conducted especially for refractory alloys. Due to the high-pressure lubricant jet, the temperature drops drastically and consequently slows down certain tool wear mechanisms [19, 20]. Machado et al. [21] reported that the machining of the Ti6Al4V alloy using high-pressure lubrication improves carbide tool life by up to $300 \%$ and ensures chip fragmentation. This achievement is the result of the reduction in diffusion wear due to the drop in cutting temperature. Similarly to carbide tools, the tool life of PCD tools can be enhanced by approximately 21 times (depending on cutting the conditions) [22]. The main tool wear mechanisms identified by the authors are adhesion and attrition. As HPWJA provides efficient lubrication of the tool/chip interface, the cutting temperature is drastically reduced. This effects surface integrity by inducing a softening effect of the machined surface $[23,24]$. A comparative study carried out by Da Silva et al. [25] has shown that neither the use of a CBN tool nor the use of a ceramic tool gives satisfactory results when machining Ti-6Al4V using HPWJA. The main tool wear mechanisms in this case are chipping, notching and cutting edge fracture. The best results have been obtained using carbide and PCD tools. As stated by Ayed et al. [26, 27], tool life can be increased up to nine times when machining Ti17 titanium alloy using HPWJA. Under these conditions, and in order to boost productivity, the cutting speed could be increased by about $30 \%$. In addition, this study demonstrated the existence of an optimum fluid pressure (100 bar) resulting in the best performance in terms of tool wear and productivity. EDS and SEM analyses of uncoated carbide tools have shown that adhesion is the main tool wear mechanism for all of the tested cutting conditions.

This study aims to investigate the impact of high-pressure water-jet-assisted machining and the cutting parameters on the machinability of the difficult-to-cut Ti555-3 (Ti-5Al$5 \mathrm{~V}-5 \mathrm{Mo}-3 \mathrm{Cr}$ ) titanium alloy. To this end, instrumented experimental tests accompanied by different analyses have been carried out.

\section{Experimental setup}

The Ti555-3 near-beta titanium alloy was selected for this study. It has improved mechanical properties compared to the Ti-10V-2Fe-3Al alloy and is mainly intended for landing gear and other aeronautical structural components. It also has high hardenability, high fracture toughness and a good strength to weight ratio $[28,29]$. The microstructure of the as-delivered material, etched with Kroll's reagent, is shown in Fig. 1. It displays a two-phase microstructure: lamellar and globular $\alpha$ phase within the $\beta$ matrix.

Longitudinal turning tests have been carried out on Leadwell LTC25iL CNC turning lathe supplying a maximum power of $24 \mathrm{~kW}$. Based on the recommendations from previous studies [5] and due to the high chemical reactivity of titanium alloys, uncoated tungsten carbide inserts (ISO designation CNMG 1204 12-23 H13A) have been used. An emulsion-based cutting fluid ( $5 \%$ concentration) has been used for the conventional lubrication tests and HPWJA tests at $100 \mathrm{bar}(15 \mathrm{l} / \mathrm{min})$ and $250 \mathrm{bar}(26 \mathrm{l} / \mathrm{min})$. Instrumented experiments have been carried out to track and to analyse tool wear evolution. A Kistler dynamometer (9257B) has been used to measure the evolution of the cutting forces. Flank wear has been measured using a stereo microscope on the basis of the standard ISO3685. The tool wear rejection criterion used is $V B=0.3 \mathrm{~mm}$ ( $V B$ represents the average flank wear). For a more comprehensive investigation of the tool wear mechanisms, a SEM and a 3D profilometer have been used. Figure 2 illustrates the experimental procedure.

On the basis of previous research concerning the machining of titanium alloys $[6,27]$, the cutting conditions, summarized in Table 1, have been selected. 


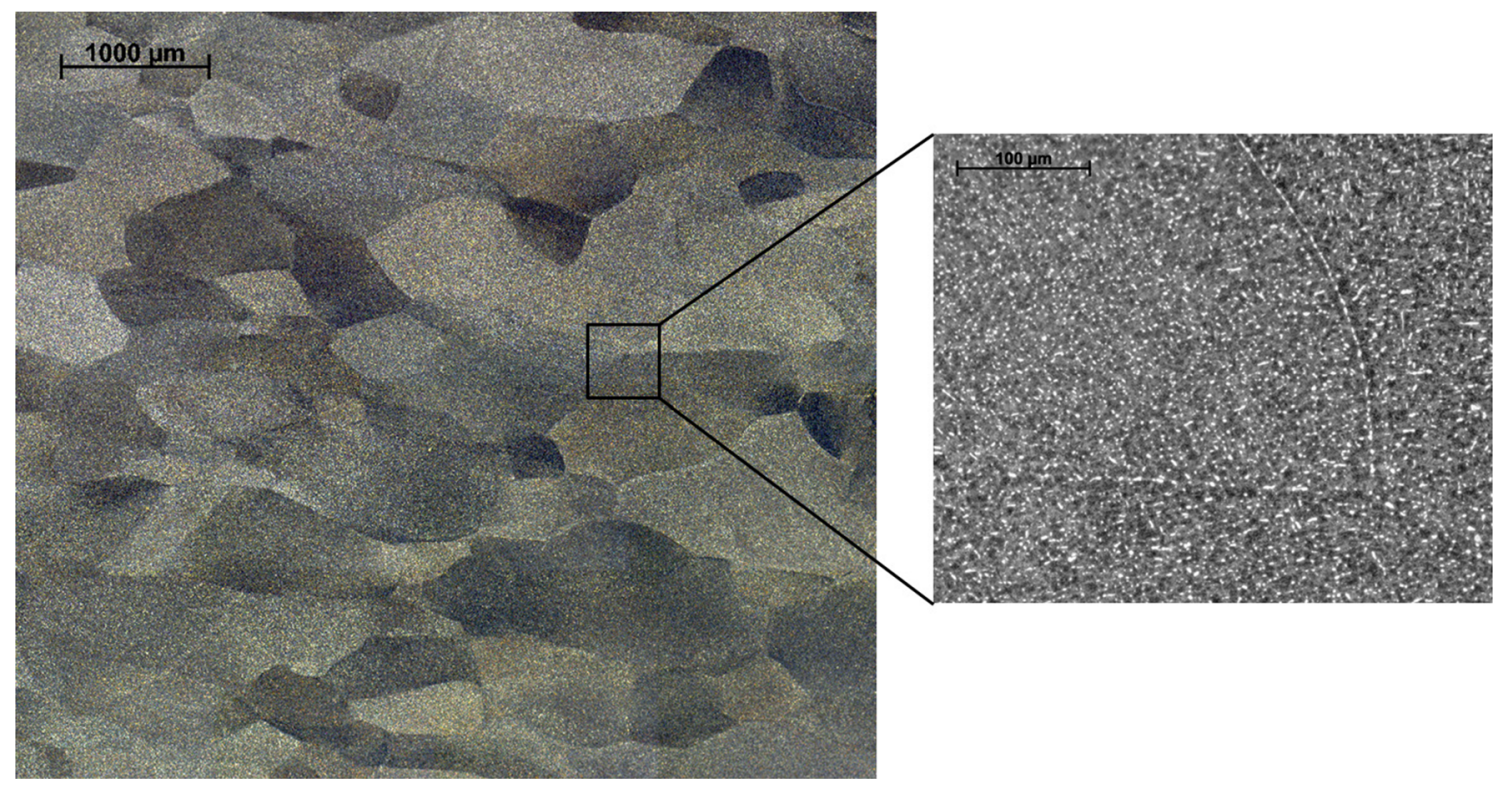

Fig. 1 Microstructure of the Ti555-3 alloy

\section{Cutting speed influence}

First of all, in order to highlight the impact of the waterjet assistance on tool life, the cutting conditions were fixed $\left(V_{c}=60 \mathrm{~m} / \mathrm{min}, a_{p}=1.5 \mathrm{~mm}\right.$ and $\left.f=0.1 \mathrm{~mm} / \mathrm{rev}\right)$. Two tests were carried out under conventional and HPWJA conditions $(P=100$ bar $)$. As showed by Fig. 3, the contribution of HPWJA can be clearly observed with an increase in tool life of up to a factor of 8 (from 4 to $34 \mathrm{~min}$ ). Based on these results, a significant gain in terms of productivity could be obtained by improving the cutting conditions. To this end, a slight increase in the cutting speed has been tested $\left(V_{c}=68 \mathrm{~m} / \mathrm{min}, V_{c}=75 \mathrm{~m} / \mathrm{min}, V_{c}=\right.$ $80 \mathrm{~m} / \mathrm{min}$ ).

Figure 3 demonstrates that the cutting speed could be further increased to $75 \mathrm{~m} / \mathrm{min}$ while maintaining an acceptable tool life of up to $11 \mathrm{~min}$. Beyond this speed, HPWJA is no longer efficient. The acceleration of wear as a consequence of an increase in cutting speed is mainly related to the activation of different tool wear mechanisms. During the cutting process, heat is generated in the cutting zone due to plastic deformation and friction. The amount of heat generated is increased by an increase in the cutting speed. As reported by Moura et al. [10],

Fig. 2 Experimental setup
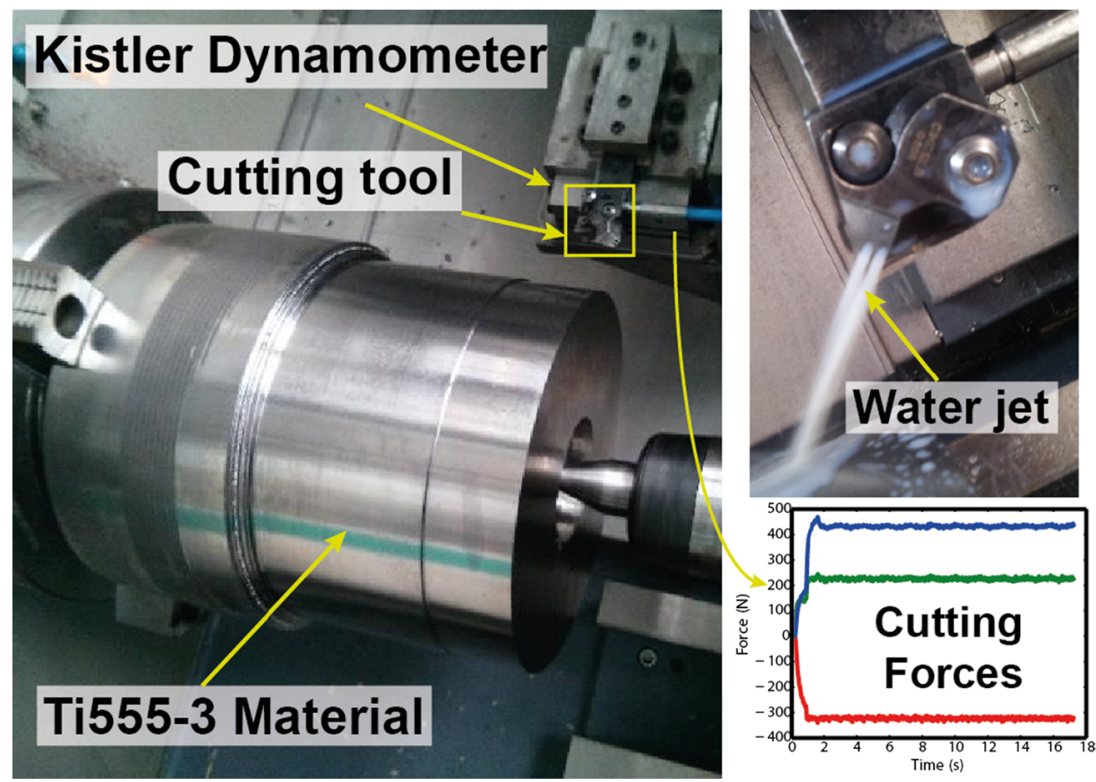
Table 1 Cutting conditions

The cutting conditions

\begin{tabular}{lll}
\hline Cutting parameters & Cutting speed $V_{c}(\mathrm{~m} / \mathrm{min})$ & $60,68,75,80$ \\
& Feed rate $f(\mathrm{~mm} / \mathrm{rev})$ & $0.1,0.2,0.25,0.3$ \\
& Depth of cut $a_{p}(\mathrm{~mm})$ & $1.5,2,2.5$ \\
Tool geometry & Nose radius $r_{\varepsilon}(\mathrm{mm})$ & 1.2 \\
& Cutting edge angle $\left(\kappa_{r}\right)$ & 95 \\
& Rake angle $\gamma\left({ }^{\circ}\right)$ & 7 \\
& Clearance angle $\alpha\left(^{\circ}\right)$ & 6
\end{tabular}

at the cutting edge, the temperature may reach $1000{ }^{\circ} \mathrm{C}$. Hence, the high temperature levels accelerate diffusion and adhesion (plucking mechanism) [10]. In the case of HPWJA, the lubricant jet insures good cooling of the cutting zone, thereby slowing tool wear evolution. However, the progressive increase of the cutting speed leads to a rapid temperature increase that the lubricant jet cannot evacuate quickly. This finally leads to a reduction of the HPWJA efficiency $(80 \mathrm{~m} / \mathrm{min})$.

This part of the study has been achieved by a comparative analysis of the impact of the lubricant-jet pressure on tool life. Figure 4 illustrates the evolution of the tool wear curves. It shows that a pressure increase causes a considerable decrease in tool life.

For both cases, observations of the tool using a stereo microscope revealed the formation of a crater at the cutting face. To get more information about tool wear evolution and mechanisms, cutting tools have been analysed using a 3D profilometer and a SEM. Figures 5 and 6 show different stages of crater formation.

For a pressure of 100 bar, tool wear evolves gradually and crater wear takes place only after 15 min of machining. However, for a pressure of 250 bar, excessive tool wear

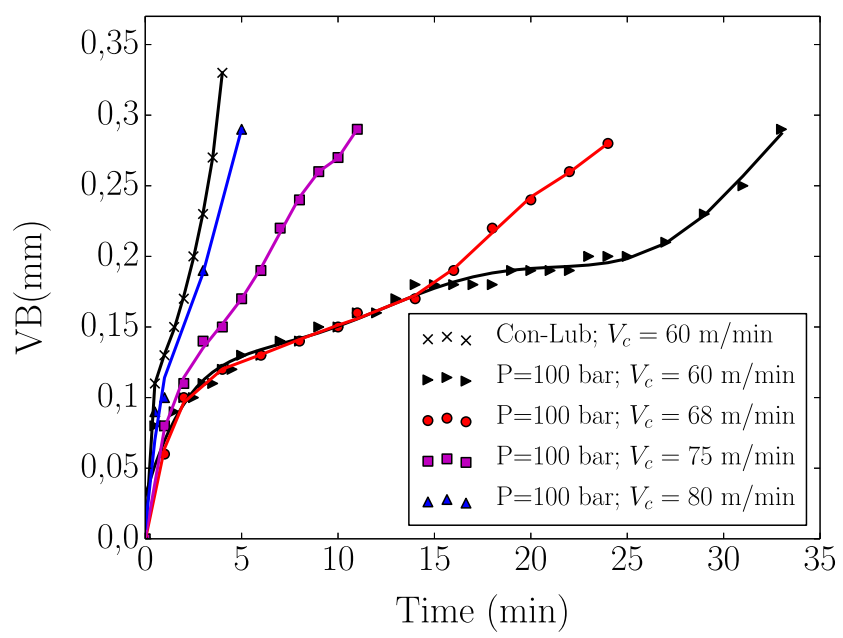

Fig. 3 Influence of the cutting speed and the high-pressure water-jet assistance on tool life ( $\left.a_{p}=1.5 \mathrm{~mm}, f=0.1 \mathrm{~mm} / \mathrm{rev}\right)$

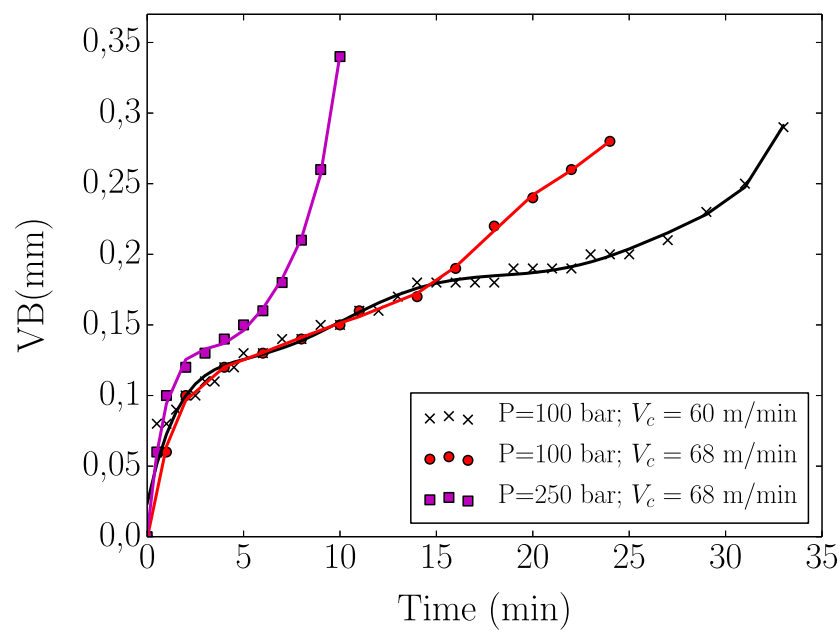

Fig. 4 Influence of the cutting speed and coolant pressure on tool life $\left(a_{p}=1.5 \mathrm{~mm}, f=0.1 \mathrm{~mm} / \mathrm{rev}\right)$

is seen, notably at the level of the tool rake face. The crater becomes larger and deeper as shows by Fig. 7. The progressive formation of the crater weakens the cutting tool. Hence, machining up to 10 min has caused the cutting edge to break and substantial material chipping.

The SEM observations, illustrated in Fig. 8, show the existence of adherent layers on the tool rake and flank faces. The parallel scratches on the tool flank face are a sign of abrasion wear. Micro-cracks have also been detected and they are mainly due the combination of tool stiffness degradation and high cutting forces.

An EDS examination of the adherent layers has confirmed the activation of an adhesion mechanism by the detection of titanium on the tool rake face as illustrated by Fig. 9. For the case of conventional machining, titanium deposits are uniformly distributed along the contact area. However, for the case of high-pressure water-jet assistance, the amount of these deposits has been greatly reduced which is mainly due to the reduction of the tool/chip contact length.

Under these cutting conditions, crater wear becomes more pronounced with the increase of the lubricant-jet pressure. Generally, the crater formation mechanism is often related to the activation and the acceleration of diffusion at high cutting temperatures [10, 30]. Optimum cutting conditions and an effective lubrication must avoid overheating of the cutting zone and thus slowdown crater formation. However, this hypothesis is inconsistent with the results found. Hence, it could be concluded that the formation of crater wear in HPWJA must be due to another mechanism. Similar results have been obtained when machining the Ti17 titanium alloy under the same lubrication conditions [26, 27]. It seems that crater formation in this case is due to an adhesion/plucking mechanism. Indeed, during machining, adherent layers are 


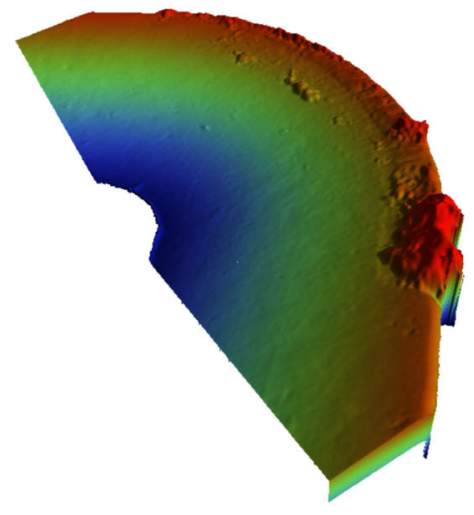

$\mathrm{T}=6 \mathrm{~min}$

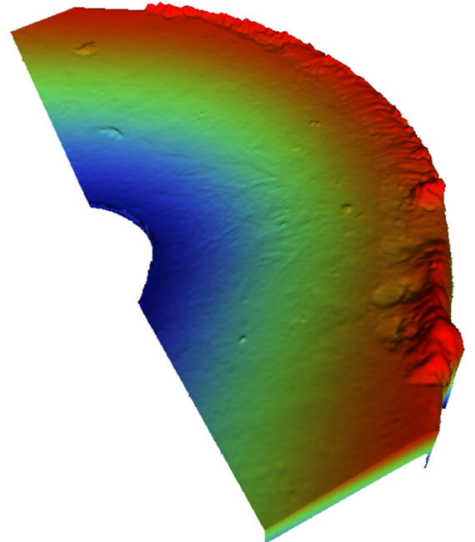

$\mathrm{T}=15 \mathrm{~min}$

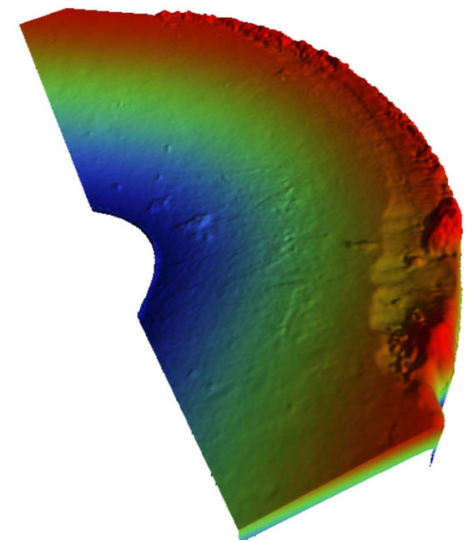

$\mathrm{T}=21 \mathrm{~min}$

Fig. 5 Tool wear evolution $(P=100$ bar $)$

formed and stick to the surface of the tool under the action of the high contact pressure and temperature. The mechanical action of the water jet causes the tearing off and plucking of these adherent layers. The increase of the water-jet pressure intensifies this phenomenon; the tool/chip contact length is more and more reduced.

The evolution of the mean arithmetic (average value) cutting force and the axial force $\left(F_{c}, F_{a}\right)$ during machining is presented in Fig. 10. It can be seen that for 100 bar, the cutting force evolves gradually. However, for 250 bar, a sharp and rapid evolution can be observed. This could be linked to flank wear, crater wear and material chipping at the cutting edge which causes a local change of the tool geometry, cutting angles and contact length.

\section{Feed rate impact}

Feed rate variation is often related to notch wear, the question now arises about the impact of high-pressure water-jet assistance on tool wear, notably at high feed rates.
At a cutting speed of $60 \mathrm{~m} / \mathrm{min}$ and a pressure of $100 \mathrm{bar}$, the feed rate has been varied from 0.1 to $0.3 \mathrm{~mm} / \mathrm{rev}$. The experimental results are plotted in Fig. 11. It shows a sharp decrease in tool life (at least 50\%); tool life does not exceed $4 \mathrm{~min}$ at $0.3 \mathrm{~mm} / \mathrm{rev}$. Also, for high feed rates, a large notch occurs and weakens the tool insert. In this context, it is necessary to point out that under these conditions and with conventional lubrication, machining of the Ti555-3 alloy is almost impossible (only $5 \mathrm{~min}$ at $0.1 \mathrm{~mm} / \mathrm{rev}$ ). Machining is accompanied by high temperature generation and smoke that ends by the collapse of the cutting edge after a few seconds.

Figure 12 emphasizes the influence of the water-jet pressure at 100 bar and 250 bar. Tests have been stopped at $\mathrm{VB}=0.23 \mathrm{~mm}$ to preserve the highly damaged cutting edge for further analysis. As well as the last tests, the increase of pressure leads to a more degradation of the tool.

Monitoring of tool wear evolution using a stereo microscope is illustrated in Fig. 13. It shows that after only $30 \mathrm{~s}$, severe wear has taken place. A notch and a crater have been formed; material chipping has been observed on

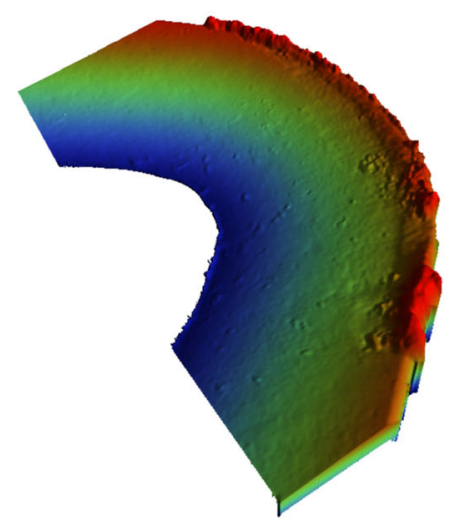

$\mathrm{T}=3 \mathrm{~min}$

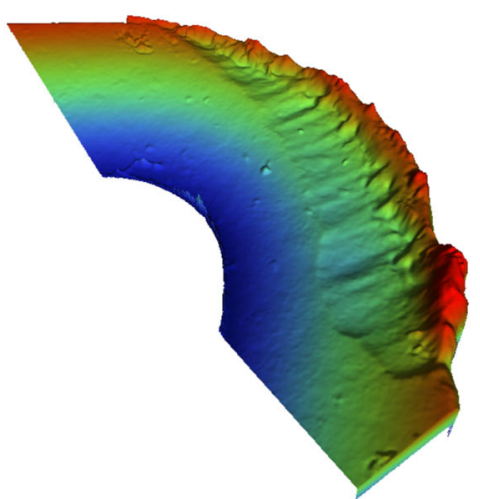

$\mathrm{T}=9 \mathrm{~min}$

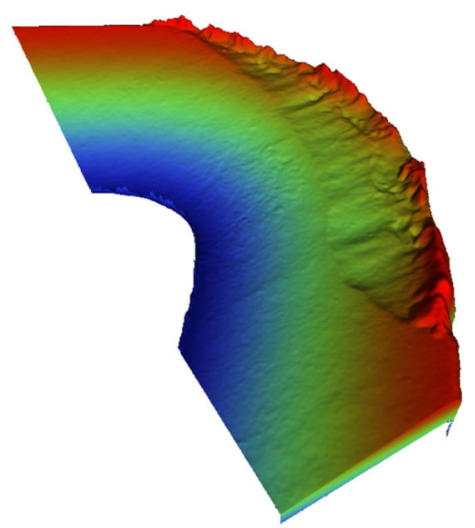

$\mathrm{T}=10 \mathrm{~min}$

Fig. 6 Tool wear evolution $(P=250$ bar $)$ 


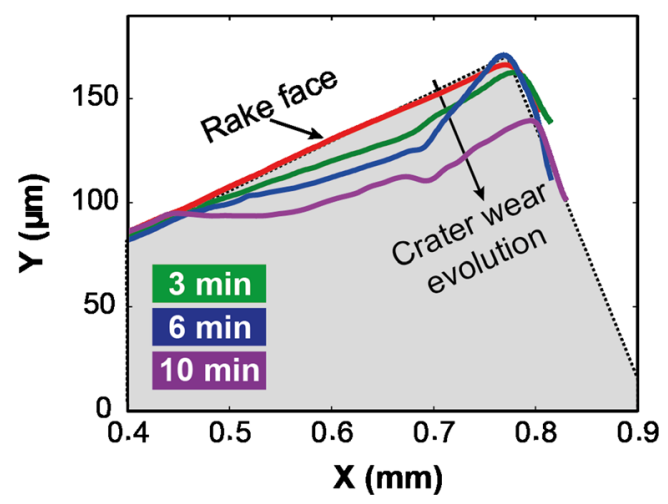

Fig. 7 Crater wear evolution $(P=250$ bar $)$

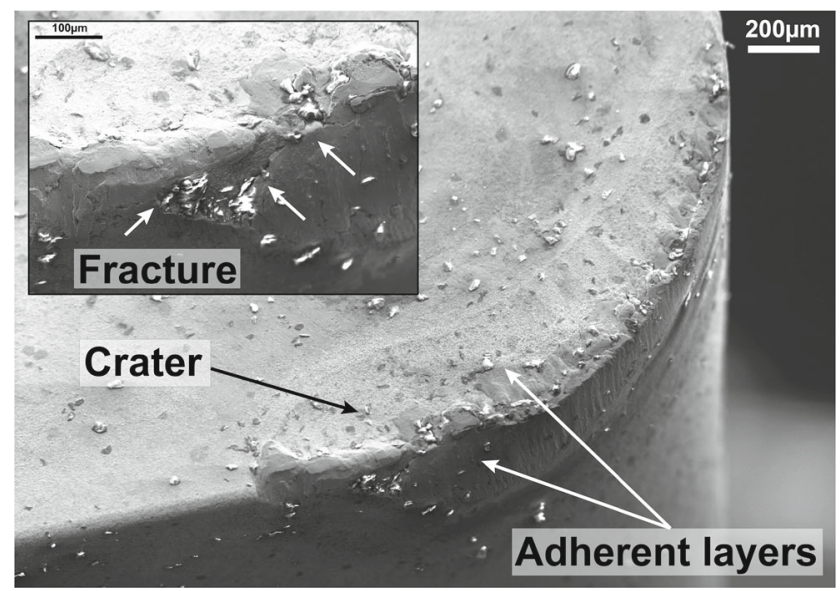

Fig. 8 SEM observation of tool wear $(P=250 \mathrm{bar}, T=9 \mathrm{~min})$
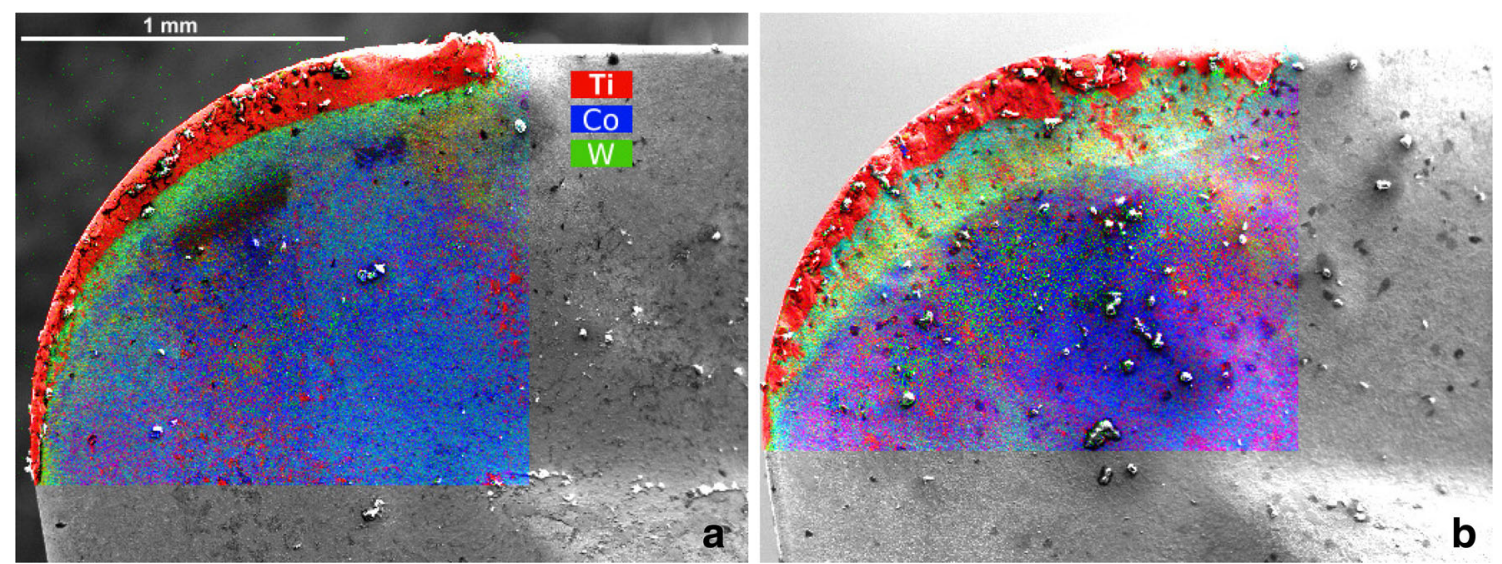

Fig. 9 SEM observation of tool wear: a Conventional lubrication, $T=4 \min ; \mathbf{b} P=250$ bar, $T=9 \min$

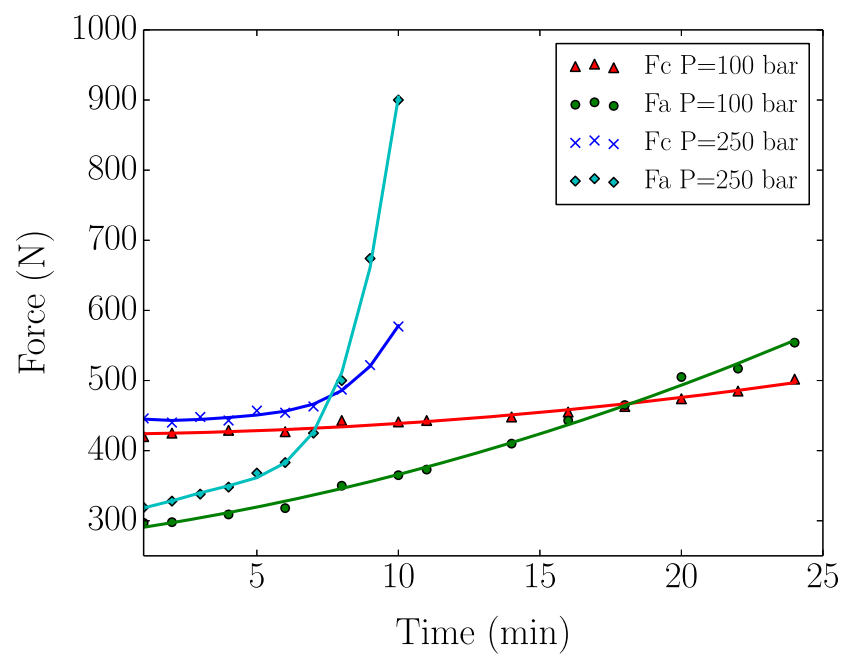

Fig. 10 Evolution of the cutting forces

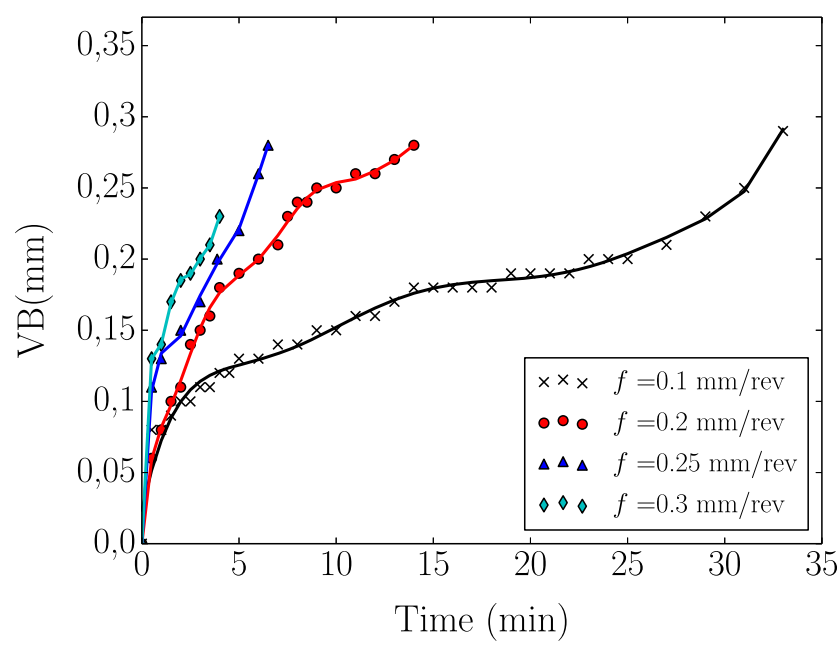

Fig. 11 Feed rate influence $\left(a_{p}=1.5 \mathrm{~mm}, V_{c}=60 \mathrm{~m} / \mathrm{min}, P=100\right.$ bar) 


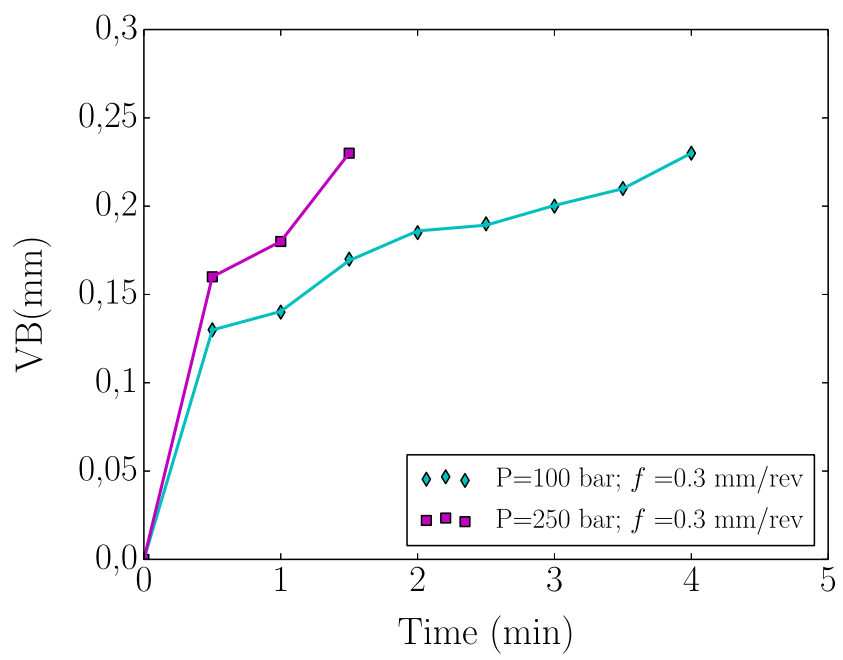

Fig. 12 Feed rate and pressure influence $\left(a_{p}=1.5 \mathrm{~mm}, V_{c}=\right.$ $60 \mathrm{~m} / \mathrm{min}$ )

the cutting edge. Over time, tool wear evolves rapidly; the notch becomes larger and reaches the crater. At this point, the tool tip becomes very fragile and it could collapse under the action of the increasing cutting forces, even if the flank wear remains stable.

For a more exhaustive tool wear analysis, tool inserts have been observed using a SEM and scanned using a 3D profilometer. Figure 14 shows the scanned surfaces of the cutting tools at the end of the tool life. Figures 15 and 16 show the SEM observations of the worn tools.

These analysis have permitted a closer view of the damaged areas. Material deposits (adherent layers) and material chipping are clearly distinguishable $(f=$ $0.2 \mathrm{~mm} / \mathrm{rev}$ and $f=0.3 \mathrm{~mm} / \mathrm{rev}$ ) on the flank face, the rake face and the notch. For a feed rate of $0.3 \mathrm{~mm} / \mathrm{rev}$, the tool seems to have undergone very severe thermo-mechanical loads, given the significant deterioration of the cutting edge. Indeed, a large notch of approximately $400 \mu \mathrm{m}$ wide and material chipping along the cutting edge have occurred in only $4 \mathrm{~min}$.

In order to explain the major notch wear mechanisms, researchers proposed many assumptions. The combination of very complex factors makes it a complicated task, which explains the big differences between the proposed hypotheses. However, experimental tests have shown that materials that have strong strain hardening behavior such as titanium alloys and nickel-base alloys are more subjected to notch wear; strain hardening, strain rate sensibility and thermal softening seem to be key contributing factors [31]. Adhesion is the most likely activated mechanism. In fact, material chipping is mainly caused by the cyclic formation of adhesive contacts and their frequency [32,33].

To explain the formation mechanisms of the notch, we assume that it occurs with the combination of all cited factors (mechanical and chemical affinity factors). For the different wear tests carried out at this stage, the water-jet assistance significantly improves tool life. The drop of the cutting temperature ensured by the high-pressure lubrication slows down some wear mechanisms (notably diffusion and adhesion). However, with the increase of the axial force (due to feed rate increase), the cutting edge is increasingly loaded in particular at the level of the depth of cut (DOC). This generates a significant stress concentration, heating, material adhesion and chipping.

\section{Depth of cut influence}

A final series of tests have been carried out in order to investigate the impact of the depth of cut on tool wear using HPWJA. The depth of cut has been varied from 1.5 to $2.5 \mathrm{~mm}\left(f=0.1 \mathrm{~mm} / \mathrm{rev}, V_{c}=60 \mathrm{~m} / \mathrm{min}\right)$. The results of these tests are presented in Fig. 17.

First of all, it could be noted that the Ti555-3 titanium alloy is almost not machinable under these cutting conditions, using conventional lubrication; the tool life does not exceed $2 \mathrm{~min}$ at $a_{p}=2.0 \mathrm{~mm}$. However, the use of the high-pressure water-jet assistance significantly increases tool life. Indeed, for $a_{p}=1.5 \mathrm{~mm}$, tool life has been multiplied by a factor of 8 and for $a_{p}=2 \mathrm{~mm}$, it has been multiplied by a factor of 10 (from 2 to $21 \mathrm{~min}$ ).

As the cutting forces increase when the depth of cut increases, it leads to a considerable increase in temperature in the cutting zone. In this very confined zone, which is subjected to very high cutting pressures, the evacuation of heat by the lubricant fluid remains very difficult. Tool wear mechanisms are then accelerated; the combined effect of temperature and mechanical actions will eventually cause plastic deformation of the cutting edge and subsequently its
Fig. 13 Observation of tool wear evolution on the tool rake face $\left(a_{p}=1.5 \mathrm{~mm}, f=0.3 \mathrm{~mm} / \mathrm{rev}\right.$, $V_{c}=60 \mathrm{~m} / \mathrm{min}, P=100 \mathrm{bar}$ )
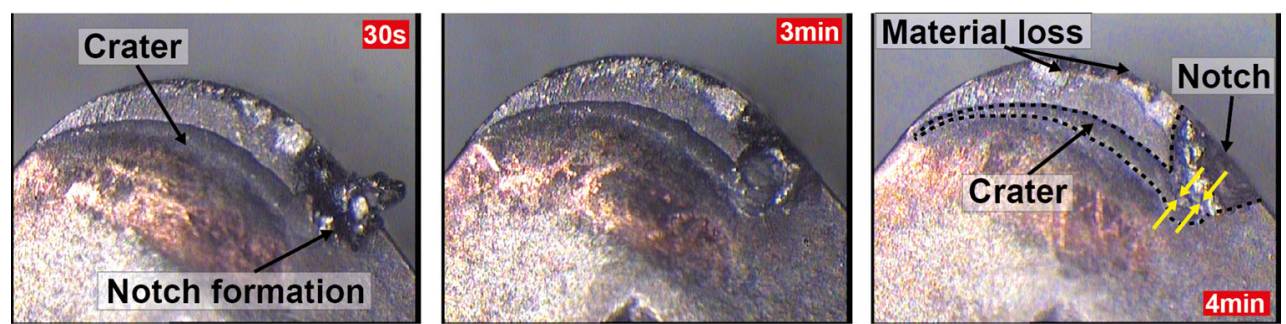


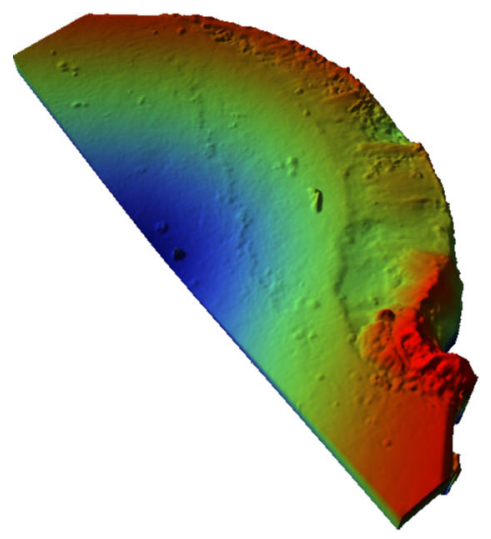

$\mathrm{f}=0.2 \mathrm{~mm} / \mathrm{rev}$

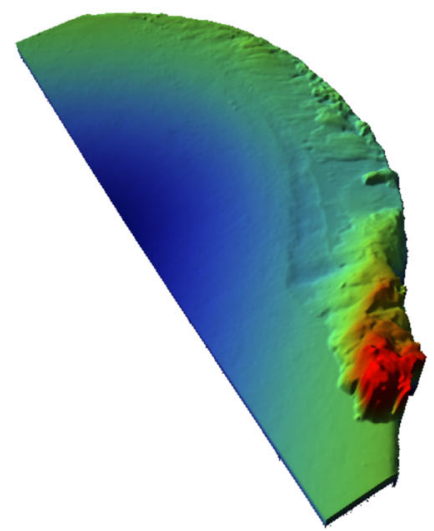

$\mathrm{f}=0.25 \mathrm{~mm} / \mathrm{rev}$

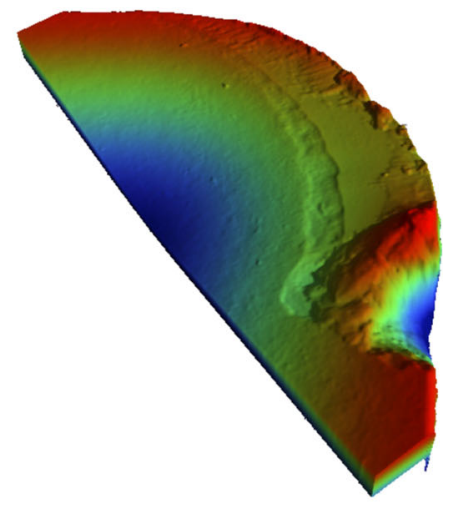

$\mathrm{f}=0.3 \mathrm{~mm} / \mathrm{rev}$

Fig. 14 Tool wear at the end of tool life ( $a_{p}=1.5 \mathrm{~mm}, V_{c}=60 \mathrm{~m} / \mathrm{min}, P=100 \mathrm{bar}$ )
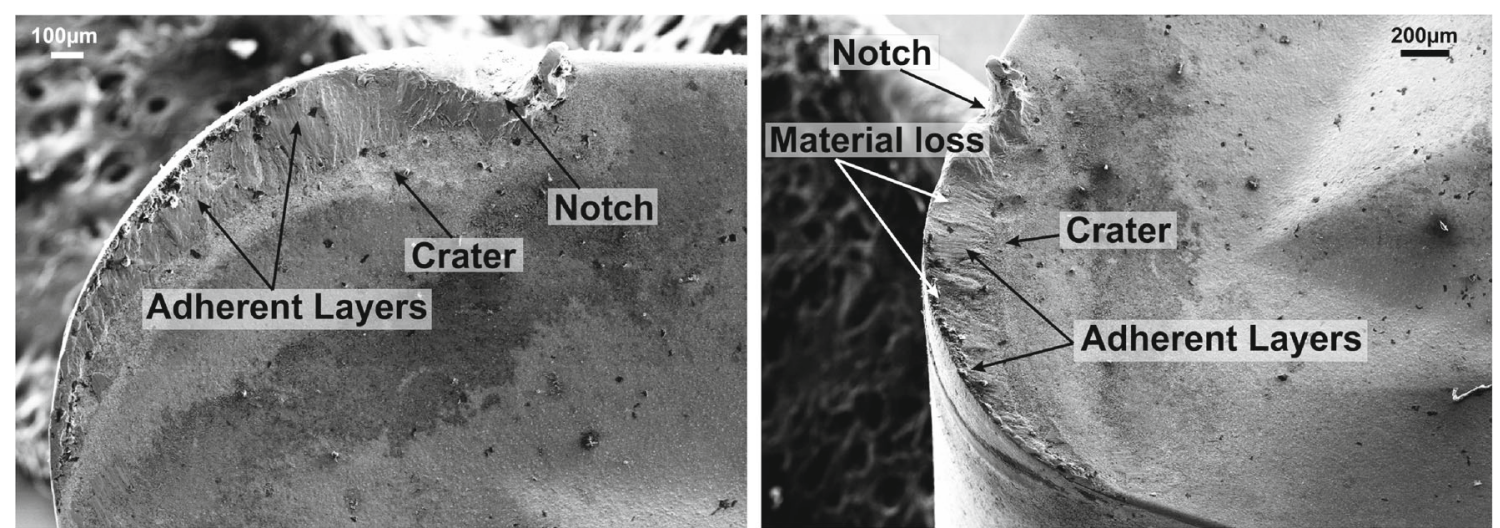

Fig. 15 Tool wear $f=0.2 \mathrm{~mm} / \mathrm{rev}\left(a_{p}=1.5 \mathrm{~mm}, V_{c}=60 \mathrm{~m} / \mathrm{min}, P=100 \mathrm{bar}\right)$
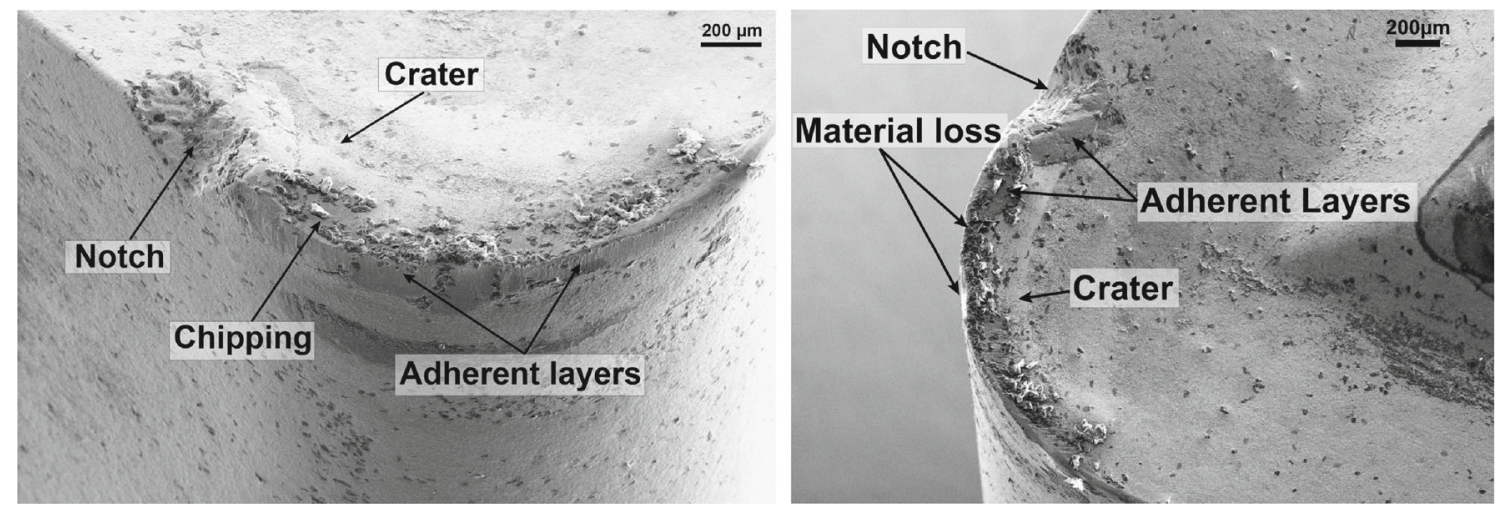

Fig. $16 f=0.3 \mathrm{~mm} / \mathrm{rev}\left(a_{p}=1.5 \mathrm{~mm}, V_{c}=60 \mathrm{~m} / \mathrm{min}, P=100 \mathrm{bar}\right)$ 


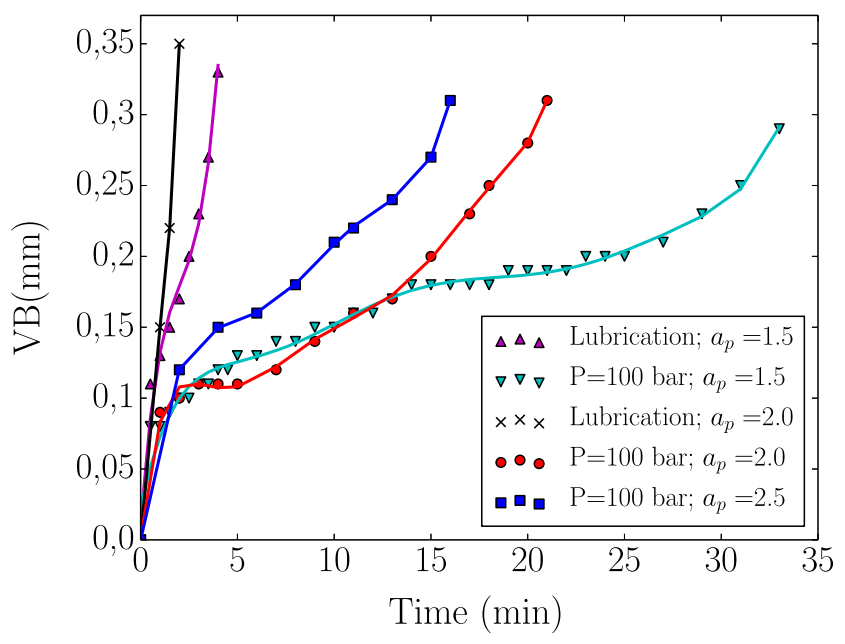

Fig. 17 Depth of cut impact ( $f=0.1 \mathrm{~mm} / \mathrm{rev}, V_{c}=60 \mathrm{~m} / \mathrm{min}$ )

collapse [34]. This has been confirmed by analyses using the SEM and the 3D profilometer. Figure 18 illustrates the plastic deformation at the cutting edge (conventional lubrication); the cutting edge has been deformed by approximately $0.15 \mathrm{~mm}$.

The evolution of the cutting forces is provided by Fig. 19. Hence, it can be deduced that the initial specific cutting force $\left(K_{c}=\frac{F}{a_{p} f}\right)$ is approximately $2800 \mathrm{MPa}$ and it reaches $3520 \mathrm{MPa}$ at the end of the tool life. This further explains the plastic deformation phenomenon which has occurred. On the bases of the work by Astakhov [34], to prevent thermal softening of tungsten carbide, the temperature should not exceed $800{ }^{\circ} \mathrm{C}$ for such a loading level. However, this temperature is far exceeded during machining of titanium alloys even for a lower cutting conditions [35]. In the case of water-jet assistance, a large part of the generated heat is evacuated.
The efficient lubrication provided by the high-pressure water jet avoids the plastic deformation wear mechanism. Figure 20 shows the rake face of the tool at the end of the tool life $(19 \mathrm{~min})$. It shows the zones of material adhesion and a large crater; it also shows micro-cracks on the border between the crater and the cutting edge. The gradual formation of the crater under the action of the adhesion mechanism (accelerated by the water jet) weakens the tool. Meanwhile, wear on rake and flank faces leads to an increase in the cutting forces. At this time, micro-cracks begin to forme; this will end by the rupture of the cutting edge.

\section{Discussion}

For conventional machining in the different tested configurations, tool life has not exceeded $5 \mathrm{~min}$. Under these conditions, the wear could be due to different mechanisms occuring simultaneously, including adhesion, diffusion, abrasion and plastic deformation. Moreover, the impact of these mechanisms differs according to the cutting conditions (roughing or finishing). During roughing machining conditions (high depth of cut) with conventional lubrication, the tool is exposed to high cutting forces combined with a high generation of heat due to plastic deformation and friction. Thus, in the cutting zone, the temperature becomes very high; the specific cutting force exceeds $2800 \mathrm{MPa}$ which leads to the plastic deformation of the cutting edge [34]. The excessive heat generation also accelerates adhesion and diffusion mechanisms [10, 30]. Similarly, the increase of the cutting speed and feed rate resulted in a very rapid degradation of tool life; the resulting temperature rise plays a key role in accelerating tool wear. Moreover, tool wear is accelerated due to the high chemical
Fig. 18 Plastic deformation of the cutting edge (conventional lubrication, $a_{p}=2 \mathrm{~mm}, T=$ $2 \mathrm{~min}$ )
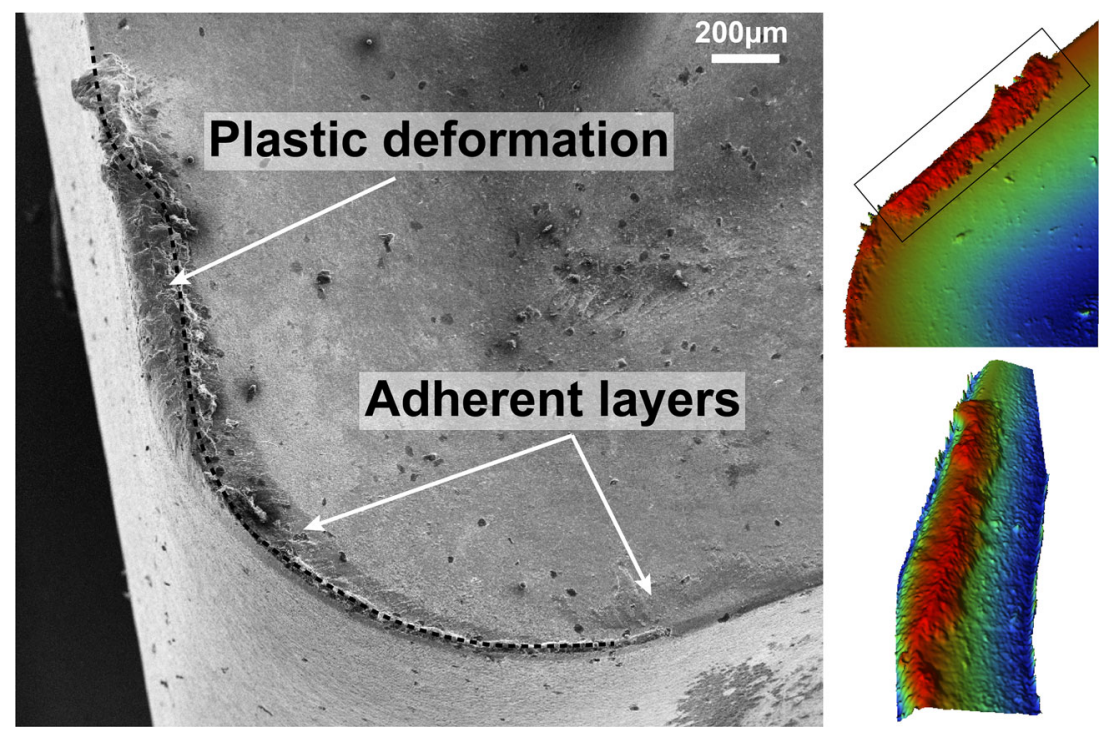


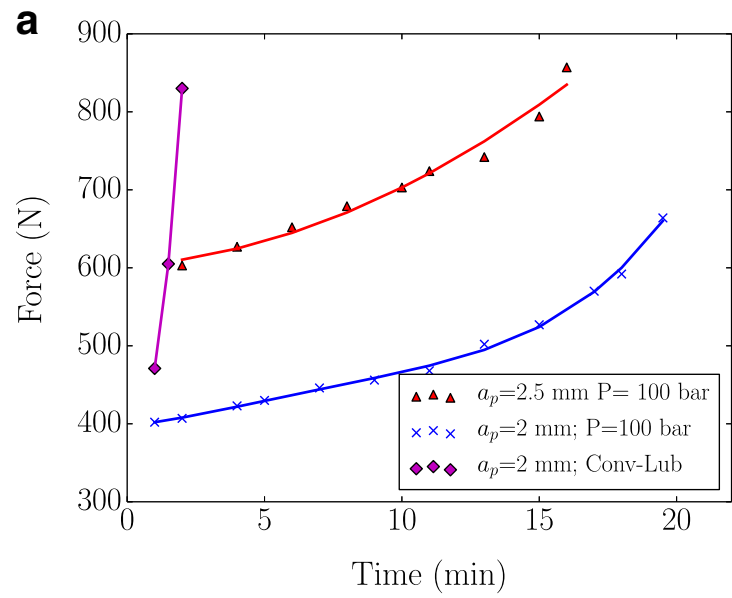

Axial force

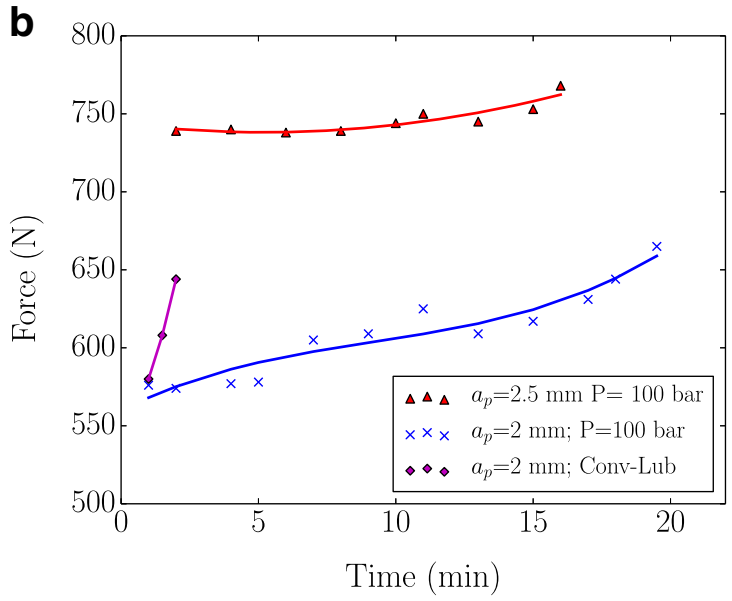

Cutting force

Fig. 19 Cutting force evolution

reactivity of the Ti555-3 alloy, its low thermal conductivity and its high sensitivity to strain rate. To cope with the increase in cutting temperature, high-pressure water-jet assistance has been used. Under these conditions, tool life has been increased up to a factor of 8 . The tool wear analysis has revealed that the main tool wear mechanisms are adhesion and abrasion. It has been noted that the deposed material layers are pulled out by the lubricant jet, thus accelerating adhesion wear. A crater is progressively formed causing a considerable degradation in tool stiffness; similar results have been obtained when machining the Ti17 titanium alloy [26]. A feed rate increase involves thermal and mechanical effects (high stress and high strain rate); HPWJA permits to slow down wear mechanisms due to thermal effects. However, increasing mechanical effects cause the acceleration of notch wear.

On the basis of the experimental results, the Taylor wear model parameters (1) have been identified for a coolant

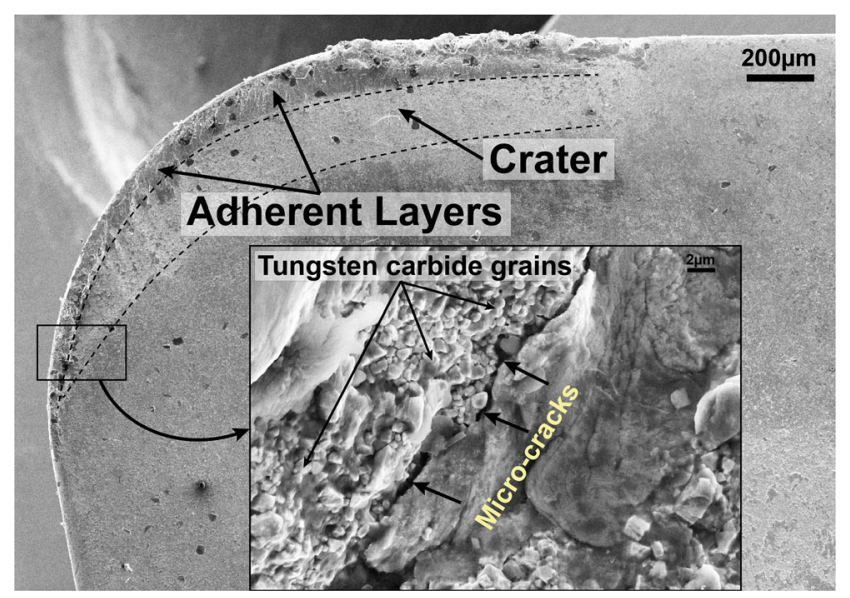

Fig. 20 Tool wear: $a_{p}=2 \mathrm{~mm}, P=100 \mathrm{bar}, T=19 \mathrm{~min}$ pressure of 100 bar. With $C=1.3610^{11}, n=-6.31$, $m=-1.87$ and $l=-1.42$.

$T=C V_{c}^{n} f^{m} a_{p}{ }^{l}$

\section{Conclusion}

The titanium alloy Ti555-3 is a difficult-to-cut material; using emulsion lubrication and for a machining time of $15 \mathrm{~min}$, the maximum cutting speed does not exceed $45 \mathrm{~m} / \mathrm{min}$ [6]. In order to enhance productivity, HPWJA has been used to asses an eventual productivity gain; a wide range of cutting conditions have been tested (cutting speed, feed rate and depth of cut). The results obtained are both interesting and promising and can be summarized in the following conclusions:

- The use of high-pressure water-jet assistance has significantly increased tool life. Under certain conditions, tool life increased by more than a factor of 8 . It is shown that very severe cutting conditions that are not possible in conventional machining become feasible using HPWJA.

- Notch wear is strongly affected by feed rate due to the high strain rate hardening sensibility of the material.

- Different experimental means have been used to monitor tool wear and to determine the major wear mechanisms. The use of 3D profilometer made it possible to track the evolution of crater wear. The analysis of SEM images and EDS analyses have been useful for determining the nature of the deposits on the tool.

- Plastic deformation, adhesion and abrasion are the main wear mechanisms under conventional lubrication conditions. 
- Adhesion remains the major wear mechanism when using the high-pressure water-jet assistance. The increase of lubricant-jet pressure lead to a tool life decrease due to the acceleration of adhesion mechanism.

Acknowledgements Authors would like to thank the company Timet (Ugine-France) for the material support given to this study.

\section{References}

1. Phapale K, Patil S, Kekade S, Jadhav S, Powar A, Supare A, Singh R (2016) Tool wear investigation in dry and high pressure coolant assisted machining of titanium alloy ti6al4 $\mathrm{v}$ with variable $\alpha$ and $\beta$ volume fraction. Procedia Manufacturing 6(Supplement C):154-159. 16th machining innovations conference for aerospace industry - MIC 2016

2. Ghosh A, Sivaprasad S, Bhattacharjee A, Kar SK (2013) Microstructure-fracture toughness correlation in an aircraft structural component alloy Ti-5Al-5V-5Mo-3Cr. Mater Sci Eng A 568:61-67

3. Nie XA, Hu Z, Liu HQ, Yi DQ, Chen TY, Wang BF, Gao Q, Wang DC (2014) High temperature deformation and creep behavior of Ti-5Al-5Mo-5V-1Fe-1Cr alloy. Mater Sci Eng A 613:306-316

4. Wagner V, Baili M, Dessein G (2015) The relationship between the cutting speed, tool wear, and chip formation during Ti-5553 dry cutting. Int J Adv Manuf Technol 76:893-912

5. Bai D, Sun J, Chen W, Wang T (2017) Wear mechanisms of WC/Co tools when machining high-strength titanium alloy TB6 (Ti-10V-2Fe-3Al). Int J Adv Manuf Technol 90:2863-2874

6. Arrazola P, Garay A, Iriarte L, Armendia M, Marya S, Maître FL (2009) Machinability of titanium alloys (Ti6Al4V and Ti555.3). J Mater Process Technol 209(5):2223-2230

7. Nouari M, Makich H (2013) Experimental investigation on the effect of the material microstructure on tool wear when machining hard titanium alloys: Ti-6Al-4V and Ti-555. Int J Refract Met Hard Mater 41:259-269

8. Ugarte A, M'Saoubi R, Garay A, Arrazola P (2012) Machining behaviour of Ti-6Al-4V and Ti-5553 alloys in interrupted cutting with PVD coated cemented carbide. Procedia CIRP 1:202-207. Fifth CIRP Conference on High Performance Cutting 2012

9. Chowdhury M, Chowdhury S, Yamamoto K, Beake B, Bose B, Elfizy A, Cavelli D, Dosbaeva G, Aramesh M, Fox-Rabinovich G, Veldhuis S (2017) Wear behaviour of coated carbide tools during machining of Ti6Al4V aerospace alloy associated with strong built up edge formation. Surf Coat Technol 313(Supplement C):319327

10. Moura RR, da Silva MB, Machado ÁR, Sales WF (2015) The effect of application of cutting fluid with solid lubricant in suspension during cutting of Ti-6Al-4V alloy. Wear 332(Supplement C):762-771. 20th International Conference on Wear of Materials

11. Rashid RR, Sun S, Wang G, Dargusch M (2012) An investigation of cutting forces and cutting temperatures during laser-assisted machining of the Ti-6Cr-5Mo-5V-4Al beta titanium alloy. Int $\mathrm{J}$ Mach Tools Manuf 63:58-69

12. Rashid RR, Bermingham M, Sun S, Wang G, Dargusch M (2013) The response of the high strength Ti-10V-2Fe-3Al beta titanium alloy to laser assisted cutting. Precis Eng 37(2):461-472

13. Ayed Y, Germain G, Salem WB, Hamdi H (2014) Experimental and numerical study of laser-assisted machining of Ti6Al4V titanium alloy. Finite Elem Anal Des 92:72-79
14. Machai C, Biermann D (2011) Machining of $\beta$-titaniumalloy Ti-10V-2Fe-3Al under cryogenic conditions: cooling with carbon dioxide snow. J Mater Process Technol 211(6):11751183

15. Bordin A, Bruschi S, Ghiotti A, Bariani P (2015) Analysis of tool wear in cryogenic machining of additive manufactured Ti6Al4V alloy. Wear 328-329:89-99

16. Lv D, Xu J, Ding W, Fu Y, Yang C, Su H (2016) Tool wear in milling Ti40 burn-resistant titanium alloy using pneumatic mist jet impinging cooling. J Mater Process Technol 229:641650

17. Shokrani A, Dhokia V, Newman ST (2016) Investigation of the effects of cryogenic machining on surface integrity in cnc end milling of Ti-6Al-4V titanium alloy. J Manuf Process 21(Supplement C):172-179

18. Ayed Y, Germain G, Melsio AP, Kowalewski P, Locufier D (2017) Impact of supply conditions of liquid nitrogen on tool wear and surface integrity when machining the Ti-6Al-4V titanium alloy. Int J Adv Manuf Technol 93:1199-1206

19. Courbon C, Kramar D, Krajnik P, Pusavec F, Rech J, Kopac J (2009) Investigation of machining performance in high-pressure jet assisted turning of Inconel 718: an experimental study. Int J Mach Tools Manuf 49(14):1114-1125

20. Kramar D, Krajnik P, Kopac J (2010) Capability of high pressure cooling in the turning of surface hardened piston rods. J Mater Process Technol 210(2):212-218

21. Machado AR, Wallbank J, Pashby IR, Ezugwu EO (1998) Tool performance and chip control when machining Ti6Al4V and Inconel 901 using high pressure coolant supply. Mach Sci Technol 2(1):1-12

22. da Silva RB, Machado AR, Ezugwu EO, Bonney J, Sales WF (2013) Tool life and wear mechanisms in high speed machining of Ti-6Al-4V alloy with PCD tools under various coolant pressures. J Mater Process Technol 213(8):1459-1464

23. Ezugwu EO, Bonney J, Silva RBD, Cakir O (2007) Surface integrity of finished turned Ti-6Al-4V alloy with PCD tools using conventional and high pressure coolant supplies. Int J Mach Tools Manuf 47(6):884-891

24. Da Silva RB, Sales WF, Costa ES, Ezugwu EO, Bonney J, Da Silva MB, Machado ÁR (2017) Surface integrity and tool life when turning of Ti-6Al-4V with coolant applied by different methods. Int J Adv Manuf Technol 93(5):1893-1902

25. da Silva RB, da Silva MB, Sales WF, Ezugwu EO, Machado ÁR (2016) Advances in the turning of titanium alloys with carbide and superabrasive cutting tools. In: Advanced materials in aerospace engineering, vol 1135 of advanced materials research. Trans Tech Publications, pp 234-254

26. Ayed Y, Germain G, Ammar A, Furet B (2013) Degradation modes and tool wear mechanisms in finish and rough machining of Ti17 titanium alloy under high-pressure water jet assistance. Wear 305(1-2):228-237

27. Ayed Y, Germain G, Ammar A, Furet B (2015) Tool wear analysis and improvement of cutting conditions using the high-pressure water-jet assistance when machining the Ti17 titanium alloy. Precis Eng 42:294-301

28. Kar SK, Suman S, Shivaprasad S, Chaudhuri A, Bhattacharjee A (2014) Processing-microstructure-yield strength correlation in a near $\beta$ ti alloy, Ti-5Al-5Mo-5V-3Cr. Mater Sci Eng A 610(Supplement C):171-180

29. Matsumoto H, Kitamura M, Li Y, Koizumi Y, Chiba A (2014) Hot forging characteristic of Ti-5Al-5V-5Mo-3Cr alloy with single metastable $\beta$ microstructure. Mater Sci Eng A 611(Supplement C):337-344

30. Odelros S, Kaplan B, Kritikos M, Johansson M, Norgren S (2017) Experimental and theoretical study of the microscopic crater wear 
mechanism in titanium machining. Wear 376(Part A):115-124. 21st International Conference on Wear of Materials

31. Kong J, Xia Z, Xu D, He N (2016) Investigation on notch wear mechanism in finish turning pure iron material with uncoated carbide tools under different cooling/lubrication conditions. Int $\mathbf{J}$ Adv Manuf Technol 86:97-105

32. Chandrasekaran H, Johansson J (1994) Chip flow and notch wear mechanisms during the machining of high austenitic stainless steels. CIRP Ann 43(1):101-105
33. Kasim M, Haron CC, Ghani J, Sulaiman M, Yazid M (2013) Wear mechanism and notch wear location prediction model in ball nose end milling of Inconel 718. Wear 302(1):1171-1179. Wear of Materials 2013

34. Astakhov V (2004) The assessment of cutting tool wear. Int $\mathbf{J}$ Mach Tools Manuf 44(6):637-647

35. Kikuchi M (2009) The use of cutting temperature to evaluate the machinability of titanium alloys. Acta Biomater 5(2):770-775 